\title{
Reducing Cultural Values to a Cost, or Adam Smith Misunderstood
}

In February 20I I the Swedish Ministry of Culture presented a suggestion for changes in the heritage law. The proposal mainly concerned the framework for the contracting of archaeological excavations related to cultural resource management (CRM). With the purpose of increasing market competition and reducing costs, the Ministry recommended that the developer should decide who should conduct the archaeological excavations in the future. These matters are today resolved by the County Administrative Boards (CAB). The suggestion was heavily criticised by a vast number of institutions and organisations including the Swedish Archaeological Society. Fortunately, the Ministry of Culture listened and withdrew the suggestion in October 20II. If it had become a reality, it would have radically transformed the conditions of Swedish archaeology to the worse.

The argumentation of the Ministry was poor in its suggestion. There is already an existing competition between different organisations performing CRM archaeology in Sweden. In today's system, the organisations interested in archaeological CRM undertakings have to present research plans and budgets to the $\mathrm{CAB}$. The price of an excavation is an important factor when the $\mathrm{CAB}$ make their decision, but the quality of the research plan is of equally great interest. The price, and not the quality, would have been the determining factor in competition if the suggestion from the Ministry of Culture had been carried out. This probably would have meant that the developer would have to hire consultants in order to find the best contractor. Today this work is done by the CAB. It is therefore not unlikely that costs would have actually increased at all ends if the suggestion of the Ministry had been ratified.

The Ministry's suggestion focused fully on costs. It did not contain any deeper reasoning related to archaeological quality. This is remarkable considering that quality normally is an important aspect to take into consideration when discussing price. The quality of the Swedish CRM 
archaeology is high today as a consequence of the last 20 years of directing scholarly and scientific ambitions. Theoretical as well as methodological standards have improved considerably across the archaeological field in Sweden, including in the university academies, thanks to CRM archaeology. The general public has largely benefited from this positive development. Popular communication and education are now concerns of priority in CRM archaeology.

Was the suggestion the result of a misunderstood reading of Adam Smith's An Inquiry into the Nature and Cause of the Wealth of Nations from I776? Smith's ideas concerning market mechanisms laid an important foundation for modern economy. However, Smith also declared that his ideas related to goods of more clear-cut commercial value, for example woollen textiles and port.

There exist other types of values apart from the strictly commercial, for example cultural values, and archaeology represents them. The laws of market mechanisms therefore give poor guidance for determining the quality of archaeology. No society can in the long run afford to propagate commercial market forces at all costs and in all contexts. It was therefore to the benefit of all when the Ministry of Culture made the wise decision to withdraw its suggestion.

Björn Magnusson Staaf, President of the Swedish Archaeological Society 